\title{
Farklı tasarımlara sahip venturilerin havalandırma performanslarının incelenmesi
}

\author{
Investigation of aeration performance in venturies with different desings
}

\author{
Sinan TURGUT ${ }^{* 1, a}$, Ö. Faruk DURSUN ${ }^{2, b}$, Mahmut AYDOĞDU $^{3, \mathrm{c}}$ \\ ${ }^{1,2}$ Inönü Üniversitesi İnşaat Mühendisliği Bölümü,44280, Malatya \\ ${ }^{3}$ Turgut Özal Üniversitesi Darende Bekir Illcak Meslek Yüksekokulu, 44280, Malatya
}

\begin{tabular}{llll}
\hline - Geliş tarihi / Received: 27.04 .2021 & •Düzeltilerek geliş tarihi / Received in revised form: 18.10 .2021 & • Kabul tarihi / Accepted: 07.11 .2021 \\
\hline
\end{tabular}

\begin{abstract}
$\ddot{O} \mathbf{z}$
Akarsularda bulunan çözünmüş oksijen miktarı, hem suyun kalitesini gösteren hem de suda yaşayan canlıların ihtiyaç duyduğu önemli bir etkendir. Hidrolik yapıların akarsular ile temas etmeleri çözünmüş oksijen miktarına önemli oranda etki etmektedir. Kaskatlar ve venturiler suların havalandırılmasında kullanılan önemli hidrolik yapılardır. Venturi sistemlerinde daralan kesit içerisinde ilerleyen suyun hızının ani bir şekilde artması ile birlikte boğaz bölgesinde negatif basınçlar oluşur. Hız değişiminin neden olduğu bu düşük basınç havayı sistem içerisine sürükler. Sistem içerisine giren hava miktarı venturi girişi-boğaz kesitleri arasındaki orana bağlı olarak değişir. Bu çalışmada, farklı havalandırma delik sayılarına sahip 36, 42 ve $54 \mathrm{~mm}$ çaplarında dairesel venturilerin performansları deneysel olarak test edilmiştir. Boğaz bölgelerinin çapı, venturi çaplarının 0.5 ve 0.75 katı, boğaz bölgesi uzunluğu ise boğaz bölgesi çapına eşit ve 2 katı olarak seçilmiş̧ir. Venturilerin üzerinde, boğaz bölgesinin orta noktasından başlayarak aralarındaki mesafe boğaz bölgesi uzunluğunun 0.75 katı olacak şekilde $6 \mathrm{~mm}$ çapında karşılıklı 3 çift delik açılmıştır. Venturilerin sistemle montajı sağlanıp sudaki Çözünmüş Oksijen Konsantrasyonu (ÇOK) üzerindeki etkileri incelenmiştir. Deneylerden elde edilen sonuçlar grafikler yardımıyla karşılaştırılarak yorumlanmıştır. Bu çalışmada, venturi çapları artarken ÇOK değerlerinin azaldığı gözlemlenmiştir. Ayrıca venturi boğaz bölgesi uzunluklarının artmasının da ÇOK değerlerini arttırdığı görülmüştür.
\end{abstract}

Anahtar kelimeler: Çözünmüş oksijen, Kütle transferi, Oksijen transferi, Suların havalandırılması, Venturimetre

\begin{abstract}
The amount of dissolved oxygen (DO) in the river is a major parameter that indicates the quality of the water and the survival of aquatic organisms. Short contact of hydraulic structures with rivers has significant effects on dissolved oxygen content. The cascades and venturies are important hydraulic structures used in the aeration of water. In venturi systems, negative pressure occurs in the throat section by means of the sudden increase of the velocity of the water in the narrowing section. The air enters into the system because of this low pressure caused by the velocity changes. The amount of air entering in the system varies depending on the ratio between the venturi inlet and throat sections. In this study, circular venturi diameters of 36, 42 and $54 \mathrm{~mm}$ having different hole configuration were used. The diameter of throat regions was determined as 0.5 and 0.75 times the diameter of the venturi and the length of the throat region was equal to and 2 times the diameter of the throat region. On the venturi, 3 pairs of holes were drilled $6 \mathrm{~mm}$ in diameter with a distance of 0.75 times the length of the throat region starting from the midpoint of the throat region. The installation of the venturi with the system carried out and the effects on the dissolved oxygen concentration in the water were investigated. The results obtained from the experiments were compared and interpreted with graphs. In the study, it was observed that while venturi diameters increased, DO values decreased. In addition, it was observed that the increase in the length of the venturi throat region also increased the $D O$ values.
\end{abstract}

Keywords: Dissolved oxygen, Mass transfer, Oxygen transfer, Aeration of water, Venturi

\footnotetext{
*a Sinan TURGUT; sinan_turgut_23@hotmail.com, Tel: (0538) 79908 81, orcid.org/0000-0002-9067-3991

${ }^{\mathrm{b}}$ orcid.org/0000-0003-3923-5205 $\quad{ }^{\mathrm{c}}$ orcid.org/0000-0002-7339-2442
} 


\section{Giriş \\ 1. Introduction}

Oksijen tüm canlıların hayati fonksiyonları için ihtiyaç duydukları en önemli elementtir. Atmosferde \%21 oranında bulunan oksijenin canlıların yaşamsal faaliyetlerini devam ettirebilmeleri için gerekli olan suyun içinde de çözünmüş halde bulunması gerekmektedir. Çözünmüş oksijen yoğunluğu; akarsu, göl, nehir ve diğer tüm su kaynakları için önemli bir parametredir. Çarpık kentleşme ve sanayileşmenin hızlı artışı gibi çeşitli nedenlerle sularda bulunan oksijen miktarının kritik seviyelere düşmesi, su kalitesi ve ekolojik denge açısından oldukça tehlikelidir. Su kirliliğine neden olan başlıca etmenler; organik kirleticiler, inorganik kirleticiler, petrol kökenli kirleticiler ve sediment kökenli kirleticilerdir. $\mathrm{Bu}$ kirleticiler arasında yer alan organik kirleticiler suyun oksijen bakımından fakirleşmesinde ilk sırada yer alır. Organik kirleticiler çoğunlukla insanların faaliyetleri sonucu sulara karıșırlar. Karıștıkları sular durgunsa bunlar suyun dibinde toplanırlar. Buna sedimentasyon adı verilir. Organik ve inorganik maddelerin bir karışımı olan sedimentler bakteriler ve diğer organizmalar için iyi bir ortamdır. Böyle ortamlarda bulunan mikroorganizmalar sudaki mevcut oksijeni kullanarak organik maddeleri parçalarlar. Aerobik parçalanma denilen bu olay neticesinde suda bulunan çözünmüş oksijen konsantrasyonunda azalma olur. $\mathrm{Bu}$ durumda sistem havadan oksijen emerek durumu telafi etmeye çalışır. Dışardan emilen bu oksijen sedimentte bulunan organik madde miktarına bağl1 artış gösteren bakterilerin ihtiyacını karşılamalıdır (Baylar, 2002; Gulliver vd., 1990; Gulliver vd., 1998).

Sudaki canlı yaşamını etkileyecek ölçüde kirletici bulunması canlı yaşamını olumsuz yönde etkilemektedir. $\mathrm{Bu}$ durumunda canlıların sağliklı bir hayat sürmeleri için atmosferdeki oksijen suya kazandırılmalı ve sudaki çözünmüş oksijen miktarı ideal seviyelere (en az $5 \mathrm{mg} /$ ) getirilmelidir. Doğal yollarla uzun mesafelerde sağlanacak bu havalandırma akarsular ve nehirler üzerine çeşitli hidrolik yapılar inşa edilerek daha kısa sürede sağlanabilmektedir. Suyun bu hidrolik yapılar ile kısa süreli temasında bile sudaki çözünmüş oksijen yoğunluğu artabilmektedir. Hızlandırılmış bu oksijen transferinin sebebi olarak da çok sayida hava kabarcığının su içine girerek su-hava temas yüzeyini arttırması gösterilmektedir. $\mathrm{Bu}$ yüzden hidrolik yapılar tasarlanırken; yapının tipi, yüksekliği ve yeri oksijen transfer verimi açısından çok önemlidir (Baylar, 2002; Ervine, 1998; Mcghee, 1991).

Akışkanlar mekaniğinde basınçlı borularda kesitten geçen debinin hesaplanması her zaman pratik olmamaktadır. Burgan, yaptığı çalışmada gerçek debi için 6 farklı gözlem yapmış, hazırladığı venturimetre deney setinde ölçülen gerçek debi ile süreklilik ve Bernoulli denklemleri kullanılarak hesaplanan teorik debi karşılaştırmıştır. Bunu yaparken de teorik debiyi gerçek debi olarak kullanabilmek için debi düzeltme katsayısından $\mathrm{Cd}$ yararlanmıştır. Yaptığı deneylerde venturimetrenin memba kısmındaki yatay mesafenin kısa olması ve kesitin daralması neticesinde meydana gelen yersel yük kaybının küçük olması nedeniyle teorik ve deneysel hesaplanan hızlar arasındaki farkın küçük olduğu mansap kısmında ise yatay mesafenin uzun olması ve kesitin genişlemesi nedeniyle sürekli yük kaybı daha büyük olduğu gözlemlemiştir. Sonuç olarak akımın mansap kısmında ölçülen kesitsel ortalama akım hız değerlerini teorik olarak hesaplanan değerlerden daha küçük çıkmıştır. (Burgan, 2020).

Suların havalandırılması ile ilgili olarak birçok araştırmacı tarafından farklı çalışmalar yapılımış ve çözünmüs oksijen konsantrasyonu, kütle transfer katsayısı gibi parametreler için çeşitli denklemler türetilmiştir. Genel olarak basamaklı kaskatlar, konduitler, su jetleri ve venturiler gibi hidrolik yapılara uygulanabilecek tasarımlar üzerinde çalışmalar yapılmıştır. Chanson ve Toombes basamaklı bir dolusavakta sıçramalı ve geçiş akım şartlarında hava girişinin deneysel araştırmaları hakkında bir çalışma yapmışlardır. Bu çalışmada nap, geçiş ve sıçramalı akımlar için büyük bir deney setinde hız, akım derinliği, hava kabarcık oranları, sürtünme katsayısı gibi parametrelerin değişim miktarlarını incelemişlerdir (Chanson ve Toombes, 2001). Baylar, Bagatur ve Emiroğlu basamaklı düşülerde nap, geçiş ve sıçramalı akım rejimlerinin içerdiği oksijen miktarının önceden belirlenmesi adı altında bir çalışma yapmışlardır. $\mathrm{Bu}$ çalışmada farklı eğimler ve basamak yükseklikleri altında nap, geçiş ve sıçramalı akım koşullarında basamaklı düşülerde oksijen transferi ve havalanma karakteristikleri araştırılmıştır (Baylar vd., 2007). Baylar ve Emiroğlu farkl1 şekilli ince kenarlı savakların hava sürükleme hız değerlerini belirlemek için bir dizi deneysel çalışma yürütmüşlerdir. Yaptıkları çalışmada üçgen şekilli özellikle, $30^{\circ}$ ince kenarlı savağın en iyi hava sürükleme hızına sahip olduğunu ifade etmişlerdir. Yazarlar, savak şeklinin, hava sürükleme hızı üzerinde önemli etkiye sahip olduğunu vurgulamışlardır (Baylar ve Emiroğlu, 
2002). Emiroğlu ve Baylar basamaklı dolusavak ve kaskat yapılarının havalandırma verimleri üzerinde bir seri deneysel çalışmalar yürütmüşlerdir. Basamaklı kaskat havalandırıcıların en yüksek verimleri $20^{\circ}$ ile $25^{\circ}$ arasındaki kaskat açılarında gözlemlenmekte olduğunu ve bu değerin optimal olarak $22^{\circ}$ açı için uygunluk gösterdiğini ifade etmişlerdir (Emiroğlu ve Baylar, 2003). Baylar farklı enkesit geometrilerine sahip savaklar ve bunların oksijen transfer verimini nasil etkilediklerini incelemiştir. Geri devirsiz sistemlerde üçgen enkesite sahip savakların diğer enkesitli savaklardan daha iyi oksijen transfer verimine sahip olduğu ve bunun kullanılabileceğini belirtmiştir (Baylar, 2003). Baylar, Emiroğlu ve Bagatur dairesel ağızlık üzerine hava delikleri yerleştirerek farklı ağızlık tipleri geliştirmiş ve bu yeni ağızlık tiplerinin mansap havuzundaki hava giriş verimine etkisini araştırmışlardır. $\mathrm{Bu}$ yeni ağızlıklar ile klasik olarak kullanılan dairesel ağızlıktan daha yüksek hava giriş verimi elde edildiğini ifade etmişlerdir. Farklı tipli savakların hava sürükleme hızı üzerinde yaptıkları çalışmalarında, bu savakların birbirinden oldukça farklı hava sürükleme hızı değerlerine sahip olduklarını göstermiş̧lerdir (Baylar vd., 2006).

\section{Gaz transfer mekanizması}

\section{Gas transfer mechanism}

Sularda gaz transferi; suya klor, çözünmüş oksijen vb. gazlar1 vermek veya $\mathrm{CO}_{2}, \mathrm{H}_{2} \mathrm{~S}$ gibi gazlar1 sulardan uzaklaştırmak anlamına gelir. Gaz transferi gaz-sıvı ara yüzeyinde meydana gelir. Transfer işlemi sıvı içindeki gaz konsantrasyonu denge durumu oluşuncaya kadar devam eder. Sıvıgaz kütle transfer işleminde kullanılan birçok teori vardır. Bu teorilerin başında çift film teorisi yer alır (Lewis ve Whitman, 1924).

\section{1. Çift film teorisi}

\subsection{Double film theory}

$\mathrm{Bu}$ teoriye göre, gaz ve sıvı fazların temas ettiği ara yüzlerin iki tarafında sıvı ve gaz olmak üzere iki film mevcuttur. Bu tabakaların dışında sıvı ve gaz fazları yer alır. $\mathrm{Bu}$ tabakalar, gaz moleküllerinin gaz ve sıv1 fazları arasındaki hareketlerine karş1 direnç gösterirler. Sıvı içerisinde çözünürlüğü az olan gazlara, gaz fazdan sıvı faza geçerken sıvı tabakası tarafından direnç gösterilir. Benzer şekilde çözünürlüğü çok olan gazlar ise gaz filminden direnç görürler (Lewis ve Whitman, 1924).

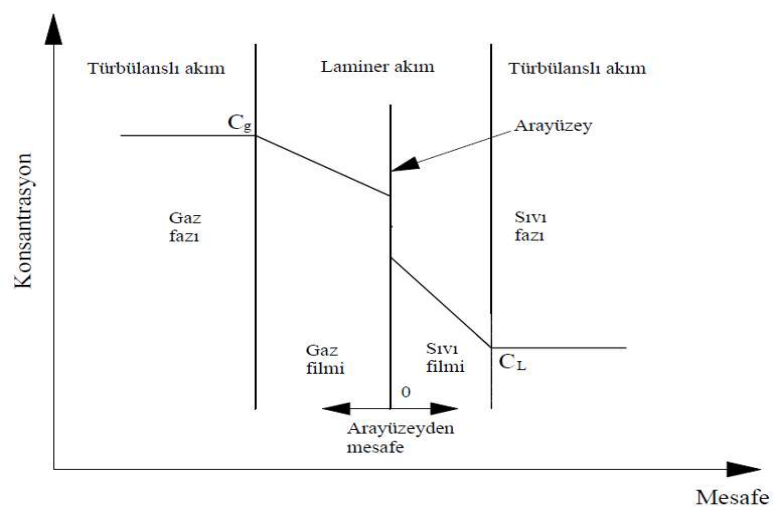

Şekil 1. Çift film teorisi (Lewis ve Whitman, 1924).

Figure 1. Double film theory (Lewis and Whitman, 1924).

Suların havalandırılmasında karşılaşılan sistemlerde genel olarak suda az çözünen gazlar söz konusu olup gaz transfer hızı, gazın denge halindeki konsantrasyonu ve mevcut konsantrasyon arasındaki farkla orantılıdır. Bu tür sistemler için gaz transfer hızı aşağıdaki gibi ifade edilir (Lewis ve Whitman, 1924).

$\frac{\mathrm{dm}}{\mathrm{dt}}=\mathrm{K}_{\mathrm{g}} \cdot \mathrm{A} \cdot\left(\mathrm{C}_{\mathrm{s}}-\mathrm{C}\right)$

Burada; $\frac{\mathrm{dm}}{\mathrm{dt}}$ : Kütle transfer hızı $(\mathrm{g} / \mathrm{s})$,

t: kütle transferinin meydana gelme süresi (s),

$\mathrm{K}_{\mathrm{g}}$ : kütle transfer katsayıs1,

A: kütle transfer alanın $\left(\mathrm{m}^{2}\right)$,

$\mathrm{C}_{\mathrm{s}}$ : sudaki çözünmüş oksijenin doygunluk konsantrasyonu $(\mathrm{mg} / \mathrm{L})$,

C: sudaki oksijen konsantrasyonu (mg/L) göstermektedir.

Kütle transfer hızı, konsantrasyon hızı cinsinden aşağıdaki gibi ifade edilir.

$\frac{\mathrm{dm}}{\mathrm{dt}}=\mathrm{V} \cdot \frac{\mathrm{dc}}{\mathrm{dt}}$

Burada; V: transfer olunan gaz hacmidir.

$\mathrm{Bu}$ ifade yukardaki denklemde yerine yazılırsa aşağıdaki denklem bulunur.

$\frac{\mathrm{dc}}{\mathrm{dt}}=\mathrm{K}_{\mathrm{g}} \cdot \mathrm{A} / \mathrm{V} \cdot\left(\mathrm{C}_{\mathrm{s}}-\mathrm{C}\right)$

Suların havalandırılması işleminde gaz tranferine esas direnç sıvı film içerisindedir. Bu nedenle $\mathrm{A} / \mathrm{V}$ 
yerine özgül ara kesit yüzeyini gösteren " $a$ " ve " $K_{s}$ " yerine ise sıvı film katsayısını gösteren " $\mathrm{K}_{\mathrm{L}}$ " kütle transfer katsayısı kullanılır. Böylece yeni denklem

$\frac{\mathrm{dc}}{\mathrm{dt}}=\mathrm{K}_{\mathrm{L}} \mathrm{a} \cdot\left(\mathrm{C}_{\mathrm{s}}-\mathrm{C}\right)$

şeklinde olur.

Burada; $\frac{\mathrm{dc}}{\mathrm{dt}}$ : konsantrasyon değişin hızı (mg/L),

$\mathrm{K}_{\mathrm{L}} \mathrm{a}$ : kütle transfer katsayıs1,

$\mathrm{C}_{\mathrm{s}}$ : sudaki çözünmüş oksijenin doygunluk konsantrasyonu (mg/L),

C: sudaki çözünmüş oksijen konsantrasyonu $(\mathrm{mg} / \mathrm{L})$

\section{Materyal ve metot \\ 3. Material and method}

$\mathrm{Bu}$ çalışmada, venturi havalandırıcıların sudaki oksijen transfer verimi üzerindeki etkileri incelenmiştir. Hazırlanan sistemde farklı çaplara, farklı daralma bölgelerine ve farklı uzunluklara sahip venturi aygitları kullanılarak geri devirli sistemlerdeki oksijen transfer verimi ve doygunluğa ulaşım süresi tespit edilmiştir.

Çalışma esnasında sürüntü madde, organik madde ve askı maddelerin oksijen transfer verimine etki etmemesi için musluk suyu kullanılmıştır. Deneylerin başlangıç aşamasında, suyun oksijen miktarını azaltmak için sodyum sülfit $\left(\mathrm{Na}_{2} \mathrm{SO}_{3}\right)$ ve kobalt klorür $\left(\mathrm{CoCl}_{2}\right)$ kullanılmış ve her bir venturi aygıtı için su yenilenmiştir.

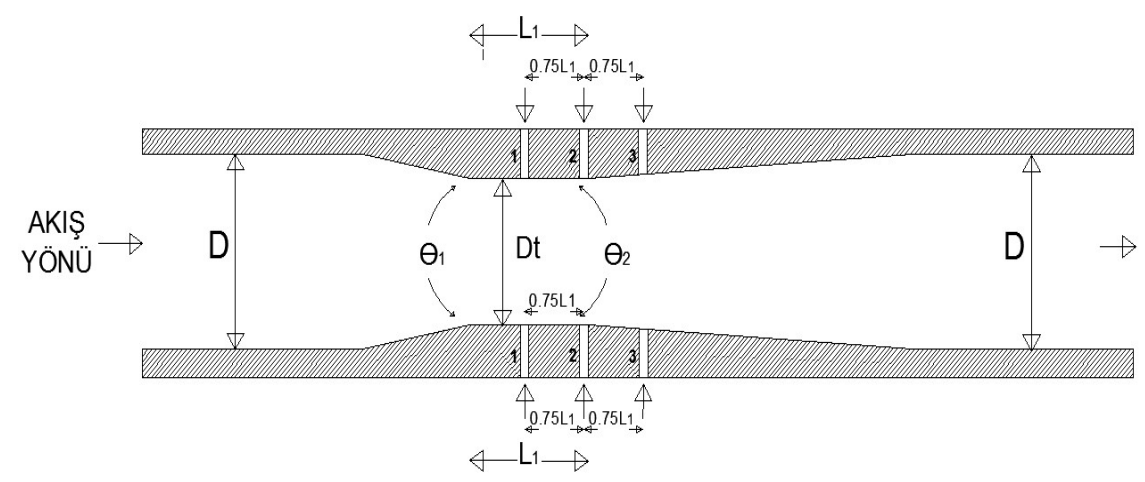

Şekil 2. Venturi aygitı enkesiti (Turgut, 2019).

Figure 2. Longiditional section of venturi (Turgut, 2019).

Deneylerde kullanilan venturilerin imal edilmesi için çelik iç kalıplar ve polyester malzeme kullanılmıştır. Venturilerin çapları 36 mm, $42 \mathrm{~mm}$ ve $54 \mathrm{~mm}$ olarak seçilmiştir. Şekil 2'de görüldüğü üzere venturi aygıtının boğaz çapı $\left(D_{t}\right)$, giriş ve çıkış çaplarının (D), 0.5 katı ve 0.75 katı olarak değişken değerlerde alınmıştır. Venturi boğaz bölgesi uzunluğu $\left(L_{1}\right)$, her bir venturi için boğaz çapı değeri $\left(\mathrm{D}_{\mathrm{t}}\right)$ ve iki katı kadar $\left(2 \mathrm{D}_{\mathrm{t}}\right)$ alınmıştır.
Akım yönüne göre venturilere ait giriş koni açıları $\theta_{1}=21^{\circ}$ ve $\theta_{2}=7^{\circ}$ olarak alınmıştır. Venturilerin boğaz bölgelerinin ortasından başlayarak venturi boğaz bölgesi uzunluğunun $\left(L_{1}\right) 0.75$ ve 1.5 katı mesafede karş111klı olmak üzere çapı $6 \mathrm{~mm}$ olan toplam 6 adet delik açılmıştır. Şekil 3'te ve Şekil 4 'te venturilere ait iç kalıplar ve hazır haldeki venturiler görülmektedir.

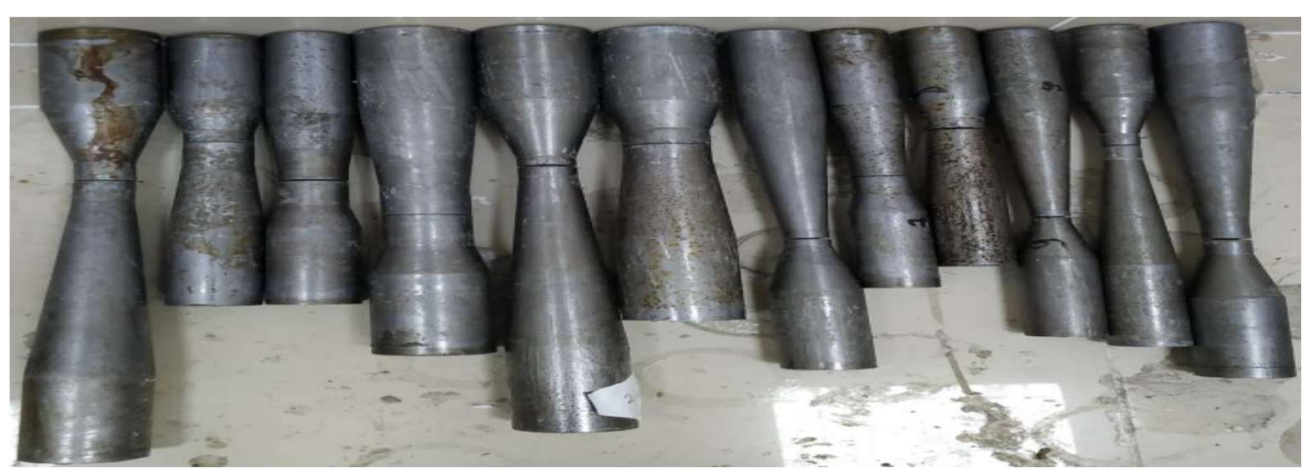

Şekil 3. Venturi iç kalıpları (Turgut, 2019)

Figure 3. Inner molds used in the manufacture of venturi (Turgut, 2019) 


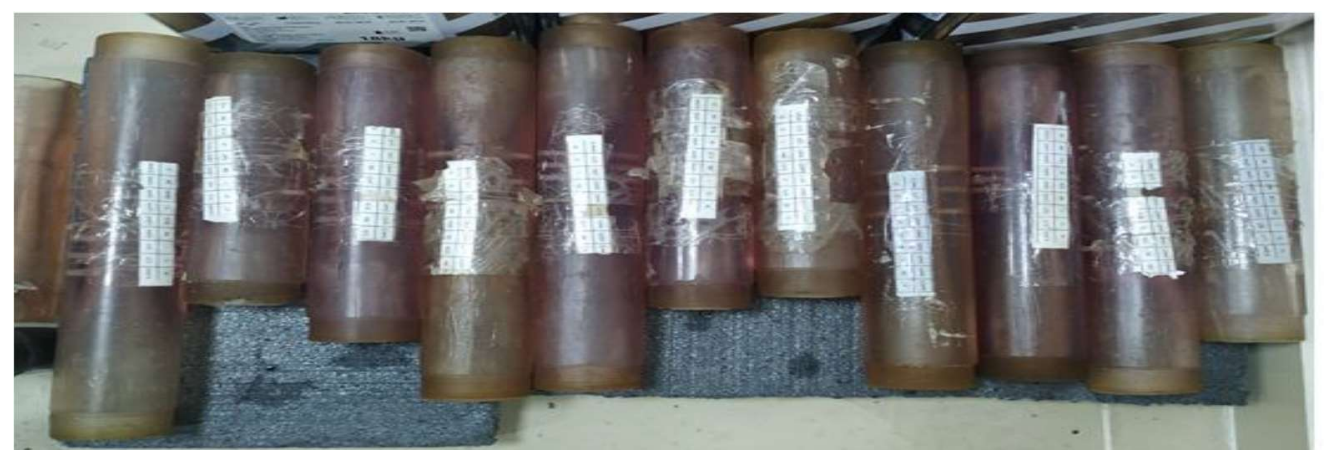

Şekil 4. İç ve dış kalıplardan ayrılmış venturiler (Turgut, 2019)

Figure 4. Venturis separated from inner and outer molds (Turgut, 2019)

Tablo 1. Deneyde kullanılan venturilere ait ölçüler (Turgut, 2019)

Table 1. Venturis separated from inner and outer molds (Turgut, 2019)

\begin{tabular}{|c|c|c|c|c|c|c|c|}
\hline $\begin{array}{c}\mathrm{D} \\
(\mathbf{m m})\end{array}$ & $\begin{array}{l}\alpha_{1} \\
\left({ }^{\circ}\right)\end{array}$ & $\begin{array}{l}\alpha_{2} \\
\left({ }^{\circ}\right) \\
\end{array}$ & $\begin{array}{c}\mathbf{D}_{\mathrm{t}} \\
(\mathrm{mm})\end{array}$ & $\begin{array}{c}L_{1} \\
(\mathbf{m m})\end{array}$ & 1. delik & $\begin{array}{c}\text { Deney isimleri } \\
\text { 2. delik }\end{array}$ & 3. delik \\
\hline \multirow{4}{*}{36} & \multirow{4}{*}{21} & \multirow{4}{*}{7} & 18 & 18 & $36-18-18-1$ & $36-18-18-2$ & $36-18-18-3$ \\
\hline & & & 18 & 36 & $36-18-36-1$ & $36-18-36-2$ & $36-18-36-3$ \\
\hline & & & 27 & 27 & $36-27-27-1$ & $36-27-27-2$ & $36-27-27-3$ \\
\hline & & & 27 & 54 & $36-27-54-1$ & $36-27-54-2$ & $36-27-54-3$ \\
\hline \multirow{4}{*}{42} & \multirow{4}{*}{21} & \multirow{4}{*}{7} & 21 & 21 & $42-21-21-1$ & $42-21-21-2$ & $42-21-21-3$ \\
\hline & & & 21 & 42 & $42-21-42-1$ & $42-21-42-2$ & $42-21-42-3$ \\
\hline & & & 31.5 & 31.5 & $42-31.5-31.5-1$ & $42-31.5-31.5-2$ & $42-31.5-31.5-3$ \\
\hline & & & 31.5 & 63 & $42-31.5-63-1$ & $42-31.5-63-2$ & $42-31.5-63-3$ \\
\hline \multirow{4}{*}{54} & \multirow{4}{*}{21} & \multirow{4}{*}{7} & 27 & 27 & $54-27-27-1$ & $54-27-27-2$ & $54-27-27-3$ \\
\hline & & & 27 & 54 & $54-27-54-1$ & $54-27-54-2$ & $54-27-54-3$ \\
\hline & & & 40.5 & 40.5 & $54-40.5-40.5-1$ & $54-40.5-40.5-2$ & $54-40.5-40.5-3$ \\
\hline & & & 40.5 & 81 & $54-40.5-81-1$ & $54-40.5-81-2$ & $54-40.5-81-3$ \\
\hline
\end{tabular}

Tablo 1'de deneyler esnasinda kullanilan venturilerin çap, boğaz bölgesi çapı, boğaz bölgesi uzunluğu ve delik durumlarına ait ölçüleri verilmiştir.

\subsection{Deney düzeneği \\ 3.1. Experimental setup}

$\mathrm{Bu}$ çalışmada $1.5 \mathrm{~m}$ uzunluğunda, $0.8 \mathrm{~m}$ genişliğinde ve $1 \mathrm{~m}$ yüksekliğinde, bir yüzü tamamen camdan imal edilmiş su tank1 kullanılmıştır. Tankın altına $70 \mathrm{~mm}$ çapında $10 \mathrm{~cm}$ uzunluğunda biri giriş (dişli) ve biri çıkış olmak üzere iki adet çelik boru kaynak ettirilmiştir. Suyun devrini sağlamak için su pompası, debi ayarlarını yapmak için kontrol vanası, sistemden geçen debiyi ölçmek için $0.01 \mathrm{~L} / \mathrm{s}$ hassasiyete sahip debimetre, enerji kayıplarını azaltmak amaciyla $100 \mathrm{~mm}$ 'den $70 \mathrm{~mm}$ ye bağlantı yapabilecek rakor, oksijen ve sıcaklı̆̆ ölçmek için dijital göstergeli oksijenmetre, tank giriş ve çıkışından pompa bağlantısı yapmak için $10 \mathrm{~m}$ uzunluğunda $100 \mathrm{~mm}$ çapında ve 2 metre uzunluğunda $70 \mathrm{~mm}$ çapında plastik borular kullanılmıştır. Şekil 5'de deney setinin şematik gösterimi verilmiştir. 


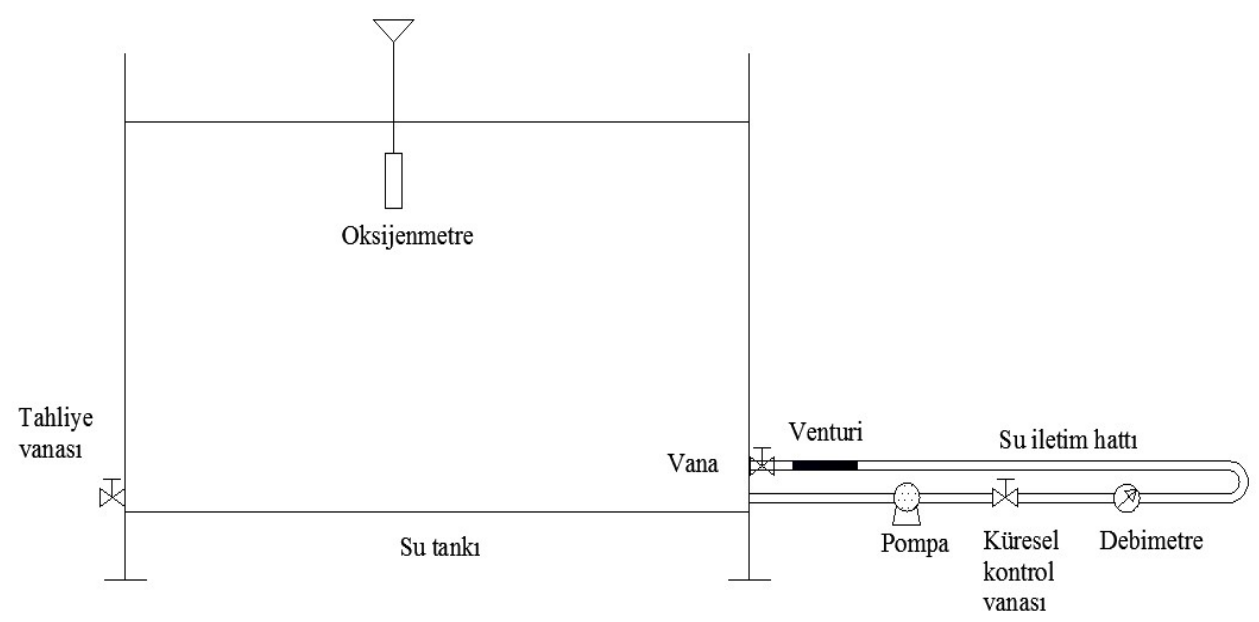

Şekil 5. Deney setinin şematik gösterimi (Turgut, 2019)

Figure 5. Shematic view of experimental setup (Turgut, 2019)

\subsection{Deneylerin yapılışı}

\subsection{Experimental studies}

Geri devirli olarak gerçekleştirilen deneyler İnönü Üniversitesi Mühendislik Fakültesi İnşaat Mühendisliği Hidrolik Laboratuvarında yapılmıştır. $70 \mathrm{~mm}$ çapındaki plastik borunun bir ucu pompa girişine diğer ucu ise su tankının çıkış kısmına bağlanmıştır. Dişli bir yapıya sahip rakorun ucuna farklı ebatlara sahip venturiler sırasıyla bağlanarak su tankının giriş kısmı ile bağlantısı yapılmıştır. Tankın içerisine su yüksekliği $0.83 \mathrm{~m}$ olacak şekilde (tanktaki su hacminin $1 \mathrm{~m}^{3}$ olması için) musluk suyu eklenmiştir. Daha sonra hacmi belli olan suyun içerisine oksijen miktarını azaltmak için $\mathrm{Na}_{2} \mathrm{SO}_{3}$ ile $\mathrm{CoCl}_{2}$ ilave edilmiştir. Su belli bir süre karıştırılıp oksijenmetre yardımıla oksijen miktarı ve sıcaklık ölçülüp not edilmiştir.

Sistem hazır hale gelince pompa çalıştırılarak debi $3 \mathrm{~L} / \mathrm{s}$ olarak ayarlanmış ve sadece 1 . delik, sadece 2. delik ve sadece 3. delik açık iken sisteme giren oksijen miktarı ölçülmüştür. Daha sonra sırasıyla 1. ve $2 ., 1$. ve $3 ., 2$. ve 3 ., ve $1 ., 2$, ve3. delikleri açıkken oksijen konsantrasyon değerlerindeki değişimler gözlemlenmiştir. Sudaki çözünmüş oksijen konsantrasyonu ideal seviyelere gelene kadar her 5 dakikada bir oksijenmetre göstergesindeki değerler okunup not edilmiştir. 3 $\mathrm{L} / \mathrm{s}$ debi için bütün deliklere ait okumalar yapıldıktan sonra debi önce $4 \mathrm{~L} / \mathrm{s}$ 'ye ve daha sonra 5 L/s'ye çıkartılarak okumalar yapılmıştır. Bir venturiye ait tüm okumalar tamamlandıktan sonra tankta bulunan su boşaltılmış ve kullanılan venturi çıkartılarak yerine yenisi takılmıştır. Böylelikle farklı çap, farklı daralma bölgesi, farklı daralma bölgesi uzunluğu ve farklı delik mesafeleri olan 12 adet venturi için 3,4 ve $5 \mathrm{~L} / \mathrm{s}$ debilerinde toplam 252 adet deney yapılmıştır.

$\left(\mathrm{K}_{\mathrm{L}} \mathrm{a}\right)_{20}=\left(\mathrm{K}_{\mathrm{L}} \mathrm{a}\right)_{\mathrm{T}}(1.024)^{(20-\mathrm{T})}$

Burada; T: sicaklık $\left({ }^{\circ} \mathrm{C}\right)$,

$\left(\mathrm{K}_{\mathrm{L}} \mathrm{a}\right)_{20}: 20{ }^{\circ} \mathrm{C}$ ve 1 atmosferdeki kütle transfer katsayıs1 (1/saat),

$\left(\mathrm{K}_{\mathrm{L}} \mathrm{a}\right) \mathrm{T}: \mathrm{T}^{\circ} \mathrm{C}$ deki kütle transfer katsayısını (1/saat) göstermektedir.

Deneylerden elde edilen veriler kullanılarak (5) nolu denklem yardımıla $\left(\mathrm{K}_{\mathrm{L}} \mathrm{a}\right)_{20}$ değerleri hesaplanmış ve oksijen transfer verimleri $\left(\mathrm{O}_{\mathrm{R}}\right)$ (6) nolu denklem yardımıyla $20{ }^{\circ} \mathrm{C}$ 'de normalize edilmiştir.

$\mathrm{O}_{\mathrm{R}}:\left(\mathrm{K}_{\mathrm{L}} \mathrm{a}\right)_{20} \times \mathrm{Cs}^{*} \times \mathrm{V} \times 10^{-3}$

denklemi ile ifade edilir.

Burada; $\mathrm{O}_{\mathrm{R}}$ : oksijen transfer oran $1\left(\mathrm{~kg} \mathrm{O}_{2} /\right.$ saat),

$\mathrm{C}_{\mathrm{s}}^{*}: 20{ }^{\circ} \mathrm{C}$ ve $1 \mathrm{~atm}$ basınç altındaki çözünmüş̧ oksijen doygunluk konsantrasyonu (mg/L), V: havalandirilan suyun hacmi ve $10^{-3}$ gramdan kilograma çevirme faktörüdür. Şekil 6 'da deneyler yapılırken takip edilen işlem sıralaması verilmiştir. 


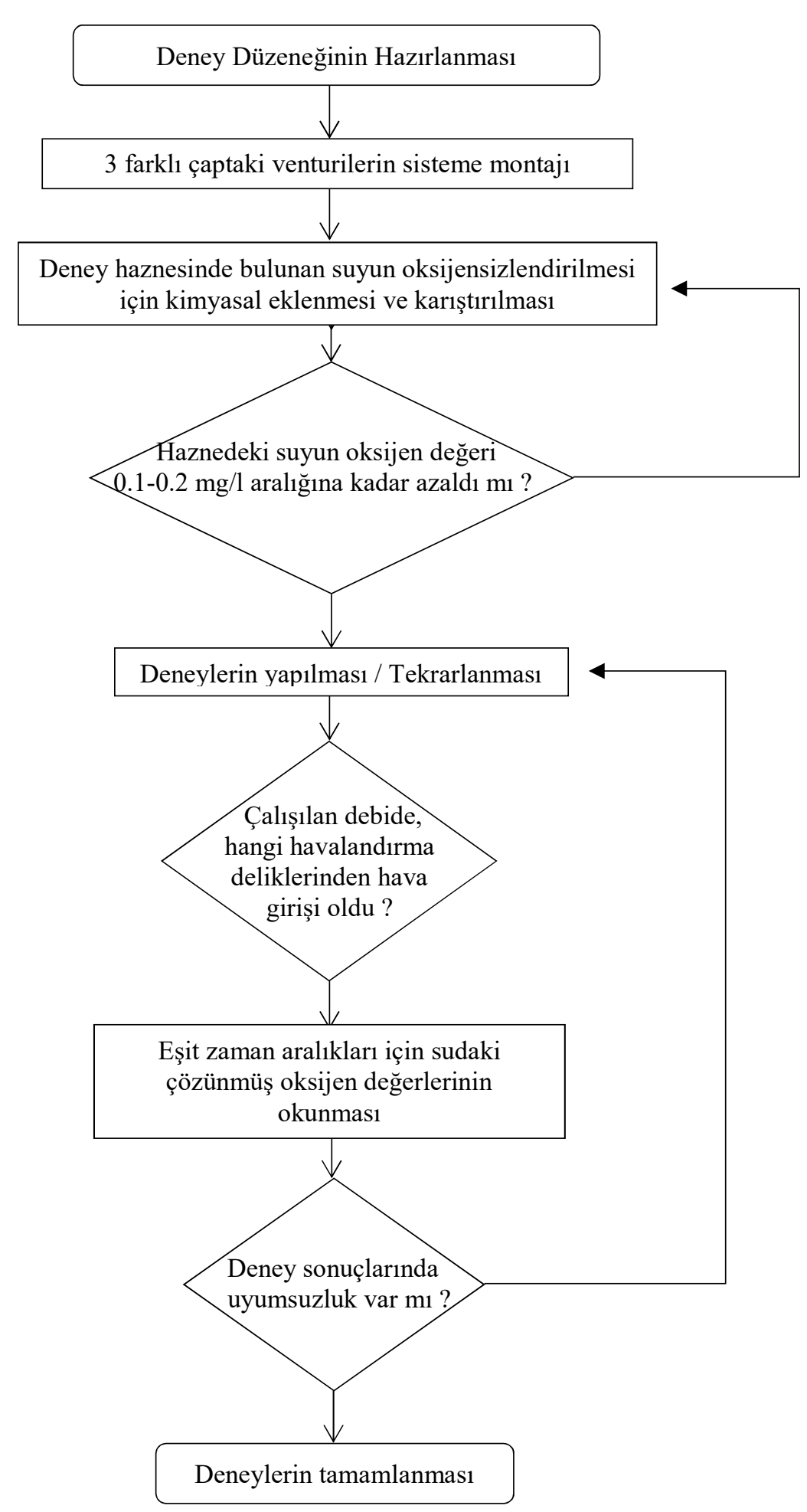

Şekil 6. Deneyler için akış şeması (Turgut, 2019)

Figure 6. Flow chart for experiments (Turgut, 2019)

\section{Bulgular \\ 4. Results}

Şekil 7'de $36 \mathrm{~mm}$ çaplı venturilerin tüm havalandırma delikleri için elde edilen oksijenlendirme oranları görülmektedir. Ters basınç yüzünden çalışmayan deneylerde çözünmüş oksijen konsantrasyon değerleri okunamamış ve bu yüzden bu çalışmalar için $\mathrm{O}_{R}$ değerleri hesaplanamamıştır. $\mathrm{O}_{\mathrm{R}}$ değeri hesaplanan deneylerde oksijenlendirme verimleri, debi değerlerinin artışına bağlı olarak değişim göstermiştir. En yüksek oksijenlendirme oranları 36-18-18-3 nolu deney için en düşük oksijenlendirme oranları ise 36-18-36- 2 ve 3 no'lu deney için elde edilmiştir. Tek delik açıkken 
yapılan deneyler için bulunan $\mathrm{O}_{R}$ değerlerinin 2 delik aynı anda açıkken bulunan $\mathrm{O}_{\mathrm{R}}$ değerlerinden

daha yüksek olduğu görülmüştür.

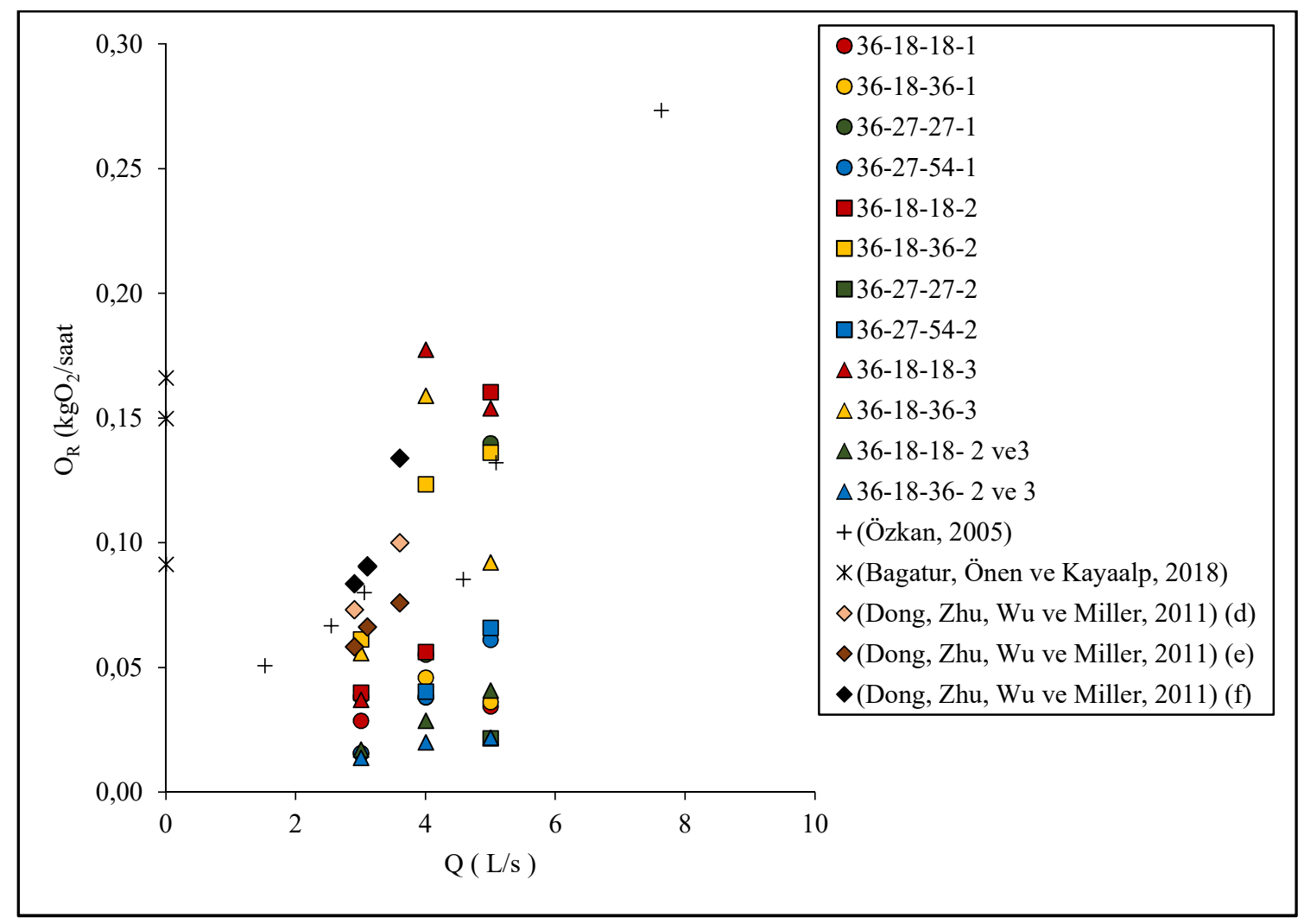

Şekil 7. $36 \mathrm{~mm}$ çaplı venturilerde tüm delikler için $\mathrm{O}_{\mathrm{R}}$ değerlerinin debiye göre değişimi (Turgut, 2019) Figure 7. Variation of $O_{R}$ values according to discharge for all holes in $36 \mathrm{~mm}$ diameter venturi (Turgut, 2019)

Ayrıca Şekil 7'de (Özkan, 2005), (Bagatur, Önen ve Kayaalp, 2018) ve (Dong, Zhu, Wu ve Miller, 2011)'un deneysel çalışmalarına ait $\mathrm{O}_{\mathrm{R}}$ değerleri de görülmektedir. (Özkan, 2005)'de $0.75 \mathrm{~m}^{3}$ su hacmi için deneyler yapılmıştır. Ancak Şekil 7'e bu değerler $1 \mathrm{~m}^{3}$ su hacmi için normalize edilerek kullanılmıştır. (Bagatur, Önen ve Kayaalp, 2018)'de 3/4 inç çapa sahip venturiler için bulunan $\mathrm{O}_{\mathrm{R}}$ değerleri kullanılmıştır. (Dong, Zhu, $\mathrm{Wu}$ ve Miller, 2011)'de ise $38 \mathrm{~mm}$ çapa sahip venturilerin 3 farklı paralel yöntemle bağlanması ile meydana gelen "modül $\mathrm{d}$, modül e ve modül $\mathrm{f}$ " için elde edilen $\mathrm{O}_{R}$ değerleri gösterilmiştir. Bu bağlamda en iyi performans (Bagatur, Önen ve Kayaalp, 2018) tarafından yapılan çalışmada elde edilmiştir. (Özkan, 2005) ve (Dong, Zhu, Wu ve Miller, 2011) bulunan sonuçlar ise ortalama değer aralığında çıkmıştır. Bu çalışmaya ait sonuçlar ile literatürde verilmiş olan sonuçlar arasında uyum olduğu görülmektedir.

Şekil 8'de $42 \mathrm{~mm}$ çaplı venturilerin tüm havalandırma delikleri için elde edilen oksijenlendirme oranları görülmektedir. Deneyler esnasında çözünmüş oksijen konsantrasyon değerleri okunamayan tüm çalışmalar için $\mathrm{O}_{R}$ değerleri hesaplanamamıştır. $O_{R}$ değeri hesaplanan deneylerde oksijenlendirme verimleri, debi değerlerinin artışına bağlı olarak değişim göstermiştir. En yüksek oksijenlendirme oranları 42-21-21-2 nolu deney için en düşük oksijenlendirme oranları ise 42-21-42- 2 ve 3 nolu deney için elde edilmiştir. Tek delik açıkken yapılan deneyler için bulunan $\mathrm{O}_{\mathrm{R}}$ değerlerinin 2 delik aynı anda açıkken bulunan $\mathrm{O}_{\mathrm{R}}$ değerlerinden daha yüksek olduğu görülmüştür.

Ayrıca Şekil 8'de (Özkan, 2005)'nin $0.75 \mathrm{~m}^{3}$ hacmindeki su ile yapmış olduğu deneysel çalışmaya ait $O_{R}$ değerlerinin debiye bağlı değişimi görülmektedir. Ancak kullanılan $\mathrm{O}_{\mathrm{R}}$ değerleri $1 \mathrm{~m}^{3}$ hacimli su için normalize edilerek grafikte gösterilmiştir. $\mathrm{Bu}$ tez çalışmasında da $\mathrm{O}_{\mathrm{R}}$ değerleri debi artışına bağlı olarak yükselmiştir. (Özkan, 2005)'nin çalışmasından elde edilen değerlerin 42 $\mathrm{mm}$ çaplı venturiler içinde en iyi performansa sahip olduğu görülmektedir. 


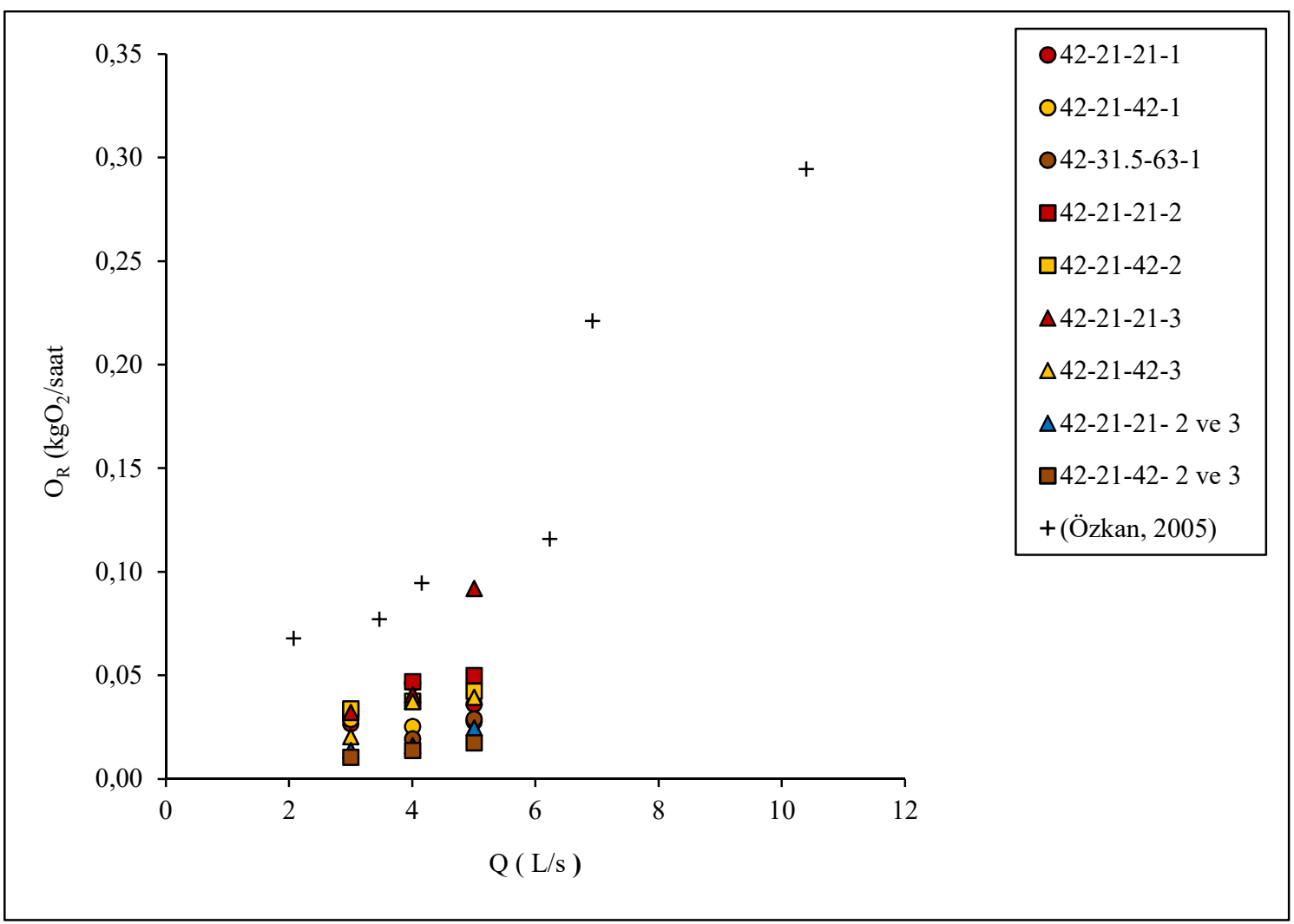

Şekil 8. $42 \mathrm{~mm}$ çaplı venturilerde tüm delikler için $\mathrm{O}_{\mathrm{R}}$ değerlerinin debiye göre değişimi (Turgut, 2019) Figure 8. Variation of $O_{R}$ values according to discharge for all holes in $42 \mathrm{~mm}$ diameter venturi (Turgut, 2019)

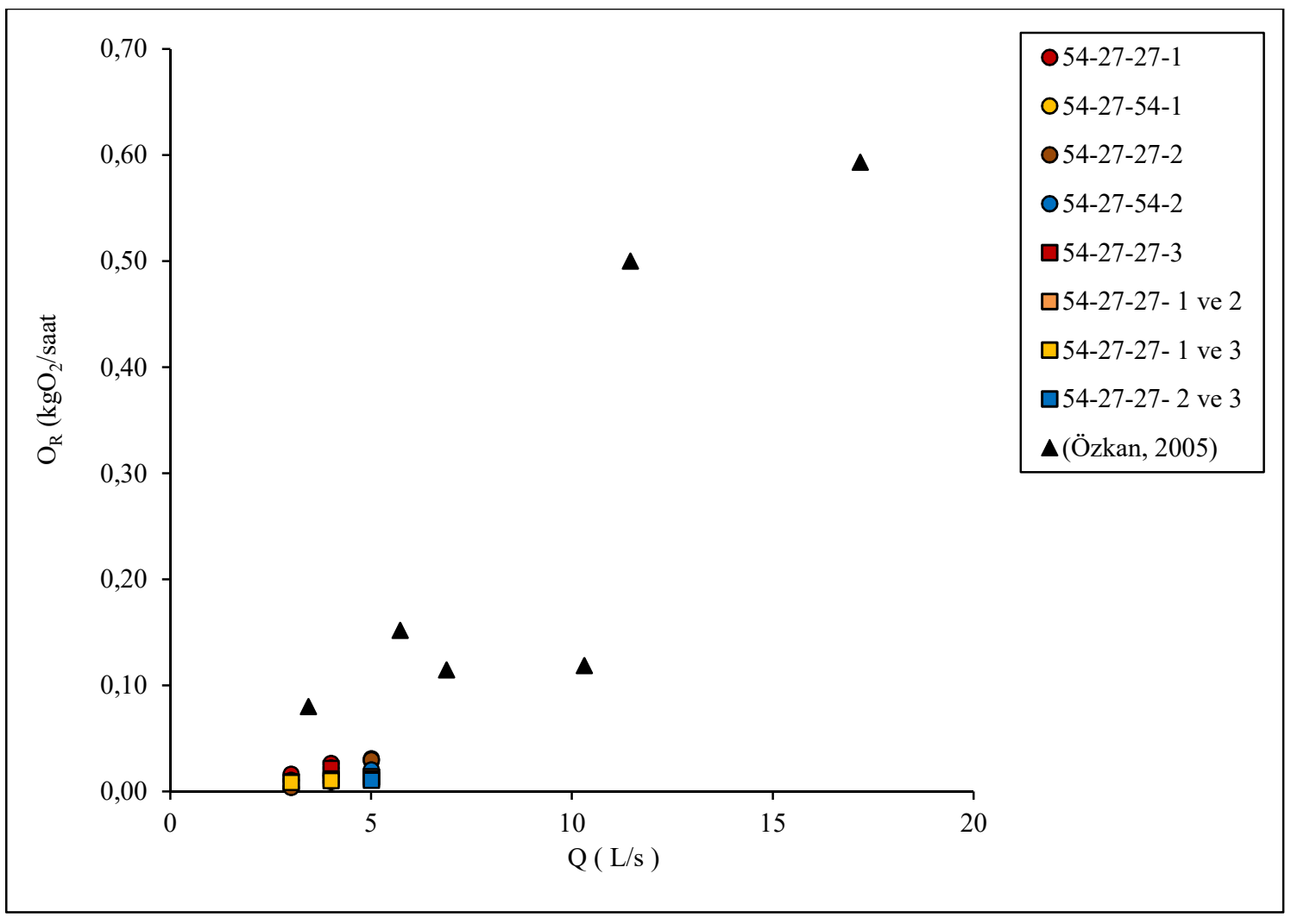

Şekil 9. $54 \mathrm{~mm}$ çaplı venturilerde tüm delikler için $\mathrm{O}_{\mathrm{R}}$ değerlerinin debiye göre değişimi (Turgut, 2019) Figure 9. Variation of $O_{R}$ values according to discharge for all holes in $54 \mathrm{~mm}$ diameter venturi (Turgut, 2019) 
Şekil 9'da $54 \mathrm{~mm}$ çaplı venturilerin tüm havalandırma delikleri için elde edilen oksijenlendirme oranları görülmektedir. $\mathrm{O}_{\mathrm{R}}$ değeri hesaplanan deneylerde oksijenlendirme verimleri, debi değerlerinin artışına bağlı olarak değişim göstermiştir. En yüksek oksijenlendirme oranları 54-27-27-1 nolu deney için en düşük oksijenlendirme oranları ise 42-21-42-1, 2 ve 3 nolu deney için elde edilmiştir. Tek delik açıkken yapılan deneyler için bulunan $\mathrm{O}_{R}$ değerlerinin 2 ve daha fazla delik aynı anda açıkken bulunan $O_{R}$ değerlerinden daha yüksek olduğu görülmüştür. Ayrıca Şekil 9'da (Özkan, 2005)'nin çalışmasından elde edilen değerlerin $54 \mathrm{~mm}$ çaplı venturiler içinde en iyi performansa sahip olduğu görülmektedir.

\section{Sonuçlar}

\section{Conclusions}

Bu çalışmada farklı çap, farklı boğaz çapı ve farklı boğaz bölgesi uzunluğuna sahip venturi tasarımları üzerinde karşılıklı $6 \mathrm{~mm}$ çaplı havalandırma delikler açılıp çözünmüş oksijen konsantrasyon değerleri incelenmiştir. Toplamda 252 adet deneysel çalışma yapılmış ve sonuçları aşağıda sunulmuştur.

Yapılan çalışmalarda en iyi sonuçların sırasıyla 36 $\mathrm{mm}, 42 \mathrm{~mm}$ ve $54 \mathrm{~mm}$ çapa sahip venturilerde olduğu görülmüştür. Yani çapın büyümesiyle verimlilik azalmıştır.

$36 \mathrm{~mm}$ çapa sahip venturilerde boğaz bölgesi uzunluğunun $l_{1}=2 \mathrm{xD}_{\mathrm{t}}$ olduğu durumlarda yüksek oksijen transfer değerleri elde edilmiştir.

$42 \mathrm{~mm}$ ve $54 \mathrm{~mm}$ çapa sahip venturilerde boğaz bölgesi uzunluğunun $L_{1}=\mathrm{D}_{\mathrm{t}}$ olduğu durumlarda yüksek oksijen transfer değerleri elde edilmiştir.

Debi değerlerinin artışına bağlı olarak tüm venturilerde çözünmüş oksijen konsantrasyon değerlerinin arttığı görülmüştür.

$36 \mathrm{~mm}$ ve $42 \mathrm{~mm}$ çaplı venturi tasarımlarında en yüksek oksijen konsantrasyon değerleri 2. delik

\section{Simgeler ve kisaltmalar}

Symbols and abbreviations açıkken, $54 \mathrm{~mm}$ çaplı venturilerde ise 1. delik açıkken sağlandığı görülmüştür.

Sadece 1 adet delik açık iken yapılan tüm deneysel çalışmalarda en az oksijen transferinin 3. delikler için olduğu görülmüştür.

2 ve daha fazla delik açıken yapılan deneylerde (36-18-18- 2 ve 3), (36-18-36- 2 ve 3), (42-21-212 ve 3$),(42-21-42-2$ ve 3$),(54-27-27-1$ ve 2$),(54-$ 27-27- 1 ve 3), (54-27-27- 2 ve 3 ) ve (54-27-27-1, 2 ve 3 ) yeterli seviyede negatif basinç oluşmuş ve venturiler suya oksijen kazandırmıştır. Diğer çalışmalarda ise sistem içerisine önemli miktarda hava girişi olmamıştır. Önemli miktarda hava girişi olmayan venturilerde akımın boğaz bölgesinde yeterince hızlanamadığı ve birden fazla sayıdaki havalandırma deliklerinin hava emme kapasitesini azalttığı düşünülmektedir.

36,42 ve $54 \mathrm{~mm}$ çapa sahip venturilerde tek delik açıken yapılan deneylerden elde edilen $\mathrm{ÇOK}-\mathrm{O}_{\mathrm{R}}$ değerlerinin genel olarak 2 ve daha fazla delik açıken yapılan deneylerden elde edilen ÇOK değerlerinden daha yüksek olduğu görülmüştür.

3 delik aynı anda sadece 54-27-27-1, 2 ve 3 nolu deneyde çalışmıştır. Bu deney için elde edilen ÇOK ve $\mathrm{O}_{R}$ değerleri yapılan diğer bütün deneylere nazaran düşük olmuştur. Bu durum delik sayısının artmasıyla sistem içine sürüklenen oksijen miktarının azaldığını göstermiştir.

Yapılan bu deneysel çalışma ile sulardaki çözünmüş oksijen miktarını arttırarak canlı yaşamının daha kaliteli bir hale getirilmesini sağlayacak farklı hidrolik tasarımların yapılabileceği görülmüştür.

\section{Teşekkür}

Acknowledgement

Bu çalışmayı, İnönü Üniversitesi BAP birimi FYL2018-1213 kod numaralı proje ile desteklemiştir.

$\begin{array}{ll}\text { ÇOK } & \text { :Č̈zünmüss oksijen konsantrasyonu } \\ d m / d t & \text { :Kütle transfer hızı }(\mathrm{mg} / \mathrm{s}) \\ K_{g} & \text { :Kütle transfer katsaylsı } \\ A & \text { :Kütle transferi için kesit alanı }\left(\mathrm{m}^{2}\right) \\ C_{s} & \text { :Sudaki çözünmüş oksijenin doygunluk konsantrasyonu }(\mathrm{mg} / \mathrm{L}) \\ C & \text { :Sudaki çözünmüş oksijen konsantrasyonu }(\mathrm{mg} / \mathrm{L})\end{array}$




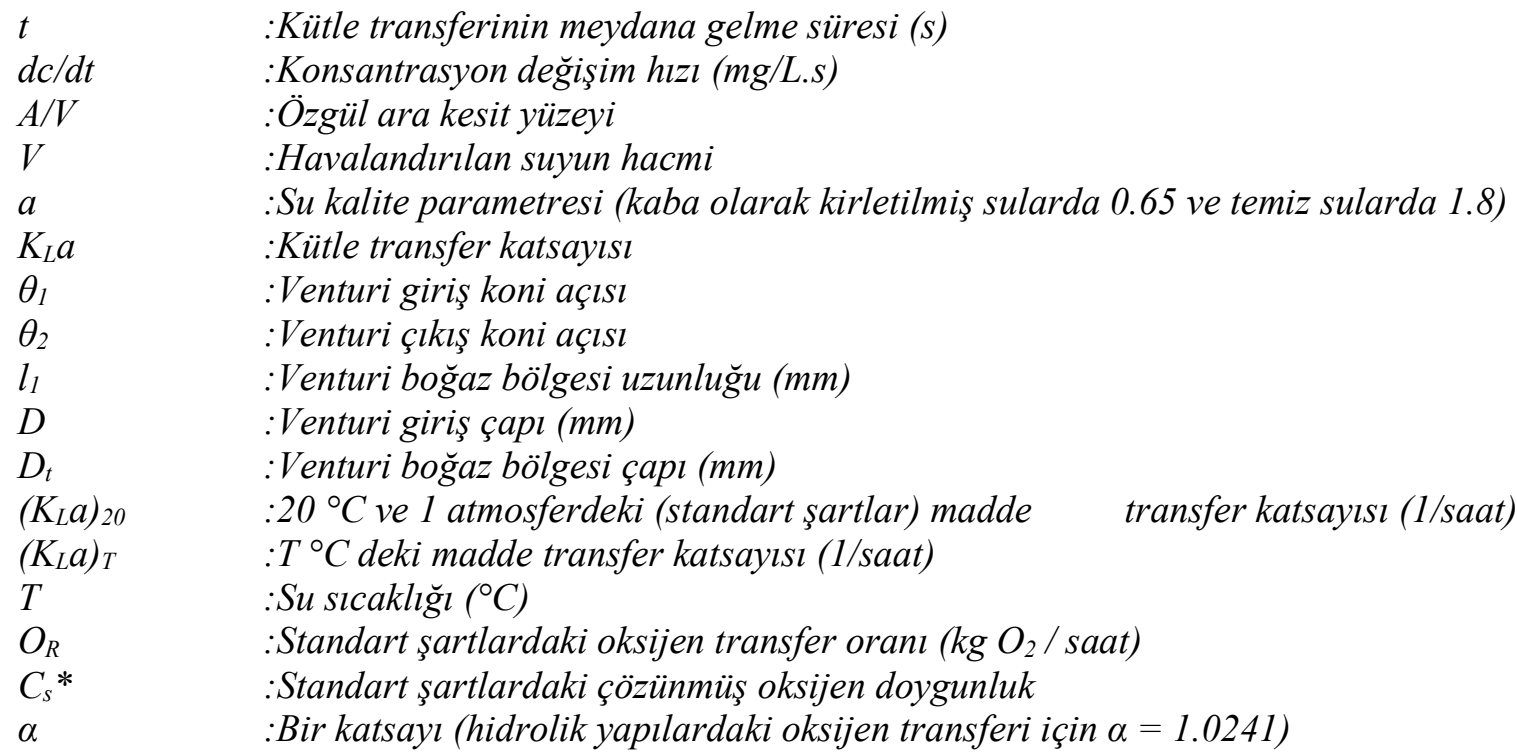

\section{Yazar katkısı}

Author contribution

Yazarlardan Sinan Turgut, deneysel çalışmaları yürütmüş ve makale yazımını gerçekleştirmiştir. Ö. Faruk Dursun deneylerin yönetilmesi ve makalenin hazırlanması aşamasında görev almıştır. Mahmut Aydoğdu ise deneysel çalışmalarda katk1 sağlamıştır.

\section{Etik beyanı}

Declaration of ethical code

Yüseköğretim Kurumları Bilimsel Ararştırma ve Yayın Etiği Yönergesi kapsamında uyulması gerekli tüm kurallara uyulduğunu, bahsi geçen yönergenin "Bilimsel Araştırma ve Yayın etiğine Aykırı Eylemler" başlı̆̆ altında belirtilen eylemlerden hiçbirinin gerçekleştirilmediğini taahhüt ederiz.

$\mathrm{Bu}$ çalışmada kullanılan materyal ve yöntemlerin etik kurul izni ve/veya yasal-özel izin gerektirmediğini beyan ederiz.

\section{Çıkar çatışması beyanı \\ Conflicts of interest}

Yazarlar herhangi bir çıkar çatışması olmadığını beyan eder.

\section{Kaynaklar}

References

Bagatur T., Önen F., \& Kayaalp N. (2018). Testing of system performance for different aerator configuration using venturi. El-Cezerî Journal of Science and Engineering, 5, 724-733. https://doi.org/10.31202/ecjse.402032
Baylar A., \& Emiroglu M.E. (2002). The effect of sharp-crested weir shape on airentrainment. Canadian Journal of Civil Engineering, 29(3), 375-383. https://doi.org/10.1139/102-017

Baylar, A. (2002). Savak havalandırıcılarda tip seçimin oksijen transferinde etkisinin incelenmesi. Doktora Tezi, Frrat Üniversitesi Fen Bilimleri Enstitüsü.

Baylar, A. (2003). An investigation on the use of venturi weirs as an aerator. Water Quality Research Journal of Canada, 38(4), 753-767. https://doi.org/10.2166/wqrj.2003.047

Baylar, A., Bagatur, T., \& Emiroğlu, M.E. (2007). Prediction of oxygen content of nappe, transition and skimming flow regimes in stepped-channel chutes. Journal Of Environmental Engineering and Science, 6(2), 201-208. https://doi.org/10.1139/s06-048

Baylar, A., Emiroglu, M. E., \& Bagatur, T. (2006). An experimental investigationof aeration performance in stepped spillways. Water and Environment Journal, 20, 35-42. https://doi.org/10.1111/j.17476593.2005.00009.x

Burgan, H.İ. (2020). Venturimetre Deneyinde gerçek ve teorik debi ilişkisi için debi düzeltme katsayısının belirlenmesi. Avrupa Bilim ve Teknoloji Dergisi, 18, 91-98. https://doi.org/10.31590/ejosat.669941

C. Dong, J. Zhu, X. Wu., \& C. F. Miller. (2011). Aeration efficiency influenced by venturi aerator arrangement, liquid flow rate and depth of diffusing pipes. School of Environmental Science and Engineering, 33, 1289-1298. https://doi.org/10.1080/09593330.2011.620986

Chanson, H., \& Toombes, L. (2001). Experimental investigations of air entrainment in transition and 
skimming flows down a stepped chute application to embankment overflow stepped spillways. Research Report No. CE 158, Department of Civil Engineering, The University of Queensland, Australia. https://doi.org/10.1139/101-084

Emiroglu, M.E., \& Baylar, A. (2003). The effect of broad-crested weir shape on air entrainment. Journal of Hydraulic Research, 41(6), 649-655. https://doi.org/10.1080/00221680309506897

Ervine, D.A. (1998) Air entrainment in hydraulic structures: a review. Proceedings of the Institution of Civil Engineers -Water, Maritime and Energy, 130, 142-153. https://doi.org/10.1680/iwtme.1998.30973

Gulliver, J.S., Thene, J.R., \& Rindels, A.J. (1990). Indexing gas transfer in self-aerated flows. Journal of Environmental Engineering ASCE, $116 \quad$ (3), 503-523. https://doi.org/10.1061/(ASCE)07339372(1990)116:3(503)

Gulliver, J.S., Wilhelms, S.C., \& Parkhill, K.L. (1998). Predictive capabilities in oxygen transfer at hydraulics structures. Journal of Hydraulic Engineering ASCE, 124 (7), 664-671. https://doi.org/10.1061/(ASCE)07339429(1998)124:7(664)

Lewis, W. K., \& Whitman, W.G. (1924). Principles of gas absorption. Proc. 68th Meeting of the American Chemical Society, September. 8-13, (pp. 1215-1220). Ithaca. https://doi.org/10.1021/ie50180a002

Mcghee, T.J. (1991). Water supply and sewerage. 6th edn McGraw-Hill International Editions, New York.

Özkan, F. (2005). Basınçlı su borularında hava iletimi ve oksijen transferinin incelenmesi. Doktora Tezi, Firat Üniversitesi Fen Bilimleri Enstitüsü.

Turgut, S. (2019). Boğaz bölgesinde farklı delik sayılarına sahip venturi aygıtının havalandırma performansınin incelenmesi. Yüksek Lisans Tezi, İnönü Üniversitesi Fen Bilimleri Enstitüsü. 